\title{
MENGGAGAS KEMBALI RUANG PUBLIK DESA (ANALISIS TERHADAP PEMANFAATAN RUANG PUBLIK PEDESAAN DI WILAYAH KABUPATEN PONOROGO)
}

\section{RECONCEPTUALIZING PUBLIC SPACE IN THE VILLAGE (THE ANALYSIS OF PUBLIC SPACE UTILIZATION IN THE VILLAGE OF PONOROGO REGENCY)}

\author{
Yusuf Adam Hilman \\ (adamhilman@umpo.ac.id) \\ (Ilmu Pemerintahan, Universitas Muhammadiyah Ponorogo)
}

\begin{abstract}
Abstrak
Pemanfaatan ruang publik sangatlah penting untuk masyarakat, keberadaan ruang publik menjadi hal yang berharga bagi orang-orang yang ingin menikmati 'kebebasan berekspresi', yang mana keberadaan ruang publik tidak hanya terbatas pada wilayah perkotaan saja, mengapa demikian, karena ruang publik pada dasarnya merupakan suatu kebutuhan manusia yang harus dipenuhi. Untuk ruang publik di perkotaan, seperti: alun-alun, taman kota, ruang bermain, ruang dilarang-merokok, serta ruang khusus untuk penyandang cacat. Sebenarnya kalau kita cermati, desa juga mempunyai ruang publik yang dapat digunakan, dan fungsinya sama seperti sarana bagi masyarakat perkotaan, meskipun di tengah rutinitas aktivitas di pertanian atau berkebun, mereka tetap membutuhkan ruang publik, yang mana bentuk dan konsep dari ruang publik di daerah pedesaan lebih sederhana, tetapi ruang publik tetap sebagai sumber dari pengetahuan masyarakat.
\end{abstract}

Kata Kunci: Menggagas Kembali, Ruang Publik, Desa

\begin{abstract}
Utilization of public spaces for community purposes is vital, given the existence becomes a precious thing amid the urgency people to enjoy 'freedom in space', that public space existence is not only limited by urban areas alone, why this is so, because the public space is basically a requirement need to be met. The public space in urban areas, such as: alun-alun square, city park, playroom, antismoking room, as well as expressive space for the disabled. In fact if we examine, the village also has a space can be used, and its function is the same as an expressive means of urban communities, although amid the routine of farming or gardening, so it needs space, that form and concept of public space in rural areas is more modest, but the public space is a source of knowledge society.
\end{abstract}

Keywords: Reconceptualizations, Public Space, Village

\section{Pendahuluan}

Pemenuhan kebutuhan masyarakat terkait akses ruang publik, terkadang sering dilupakan oleh sebagian masyarakat, padahal fungsinya sangat vital. Mari kita sejenak bayangkan, di daerah kita pasti ketika sore menjelang, atau siang hari, banyak anak - anak kecil yang sangat asik bermain layang-layang di pinggir jalan, padahal kita ketahui bahwa saat ini volume kendaraan di Indonesia sangatlah padat, setiap detik kendaraan roda dua atau roda tiga hilir mudik ataupun lalu - lalang tanpa henti, dan terkadang banyak yang memacu kendaraanya

melebihi batas minimum yang dianjurkan, sehingga terkadang anak - anak menjadi korban kecelakaan, jika kemudian sertamerta menyalahkan si anak menurut penulis kurang adil, mengingat saat ini akses ruang publik yang ada sangat minim, karena beberapa wilayah di Indonesia, lahan - lahan kosong atau yang sifatnya seperti lapang, sudah banyak yang habis karena pembangunan, jika pun ada ruang publik kemudian tidaklah gratis karena masyarakat harus masuk ke pusat - pusat perbelanjaan modern, yang tentunya tidak akan mampu terjangkau oleh masyarakat 
ekonomi menengah ke bawah. Peristiwa ini merupakan salah satu contoh, bagaimana sebuah wilayah tidak lagi mampu mengupayakan ruang untuk kepentingan masyarakatnya umum, supaya dapat menyalurkan ekspresi dan berbagai kreatifitasnya, secara maksimal tanpa ada halangan, suatu apapun.

Ilustrasi di atas merupakan salah satu bentuk kegagalan dari pemerintah, pihak swasta dan juga masyarakat dalam melakukan pengelolaan lingkuangan yang ada di wilayah tersebut, fenomena ini hampir bisa kita jumpai di berbagai daerah perkotaan yang ada di Indonesia. Dinamikanya sangatlah kompleks, hal tersebut tidak bisa dilepaskan dengan aktifitas yang dilakukan oleh masyarakat, yang begitu padatnya, dengan berbagai rutinitas pekerjaaan selama 6 (enam) hari dalam (satu) 1 minggu, sehingga dengan adanya ruang publik, masyarakat menjadi sangat terwadahi dan merasa dipedulikan, karena mereka tidak harus jauh - jauh di luar kota, dengan pertimbangan biaya yang mahal, dan juga jarak temput yang jauh serta menyita waktu, dikarenakan mereka harus kembali bekerja di hari senin - nya, dengan adanya ruang publik, di daerah perkotaan, mereka dapat melakukan berbagai kegiatan yang disukai, selain itu ruang publik juga dapat dijadikan wahana untuk saling berkomunikasi antar warga di daerah perkotaan, yang terkadang di identikan dengan masyarakat yang individualis, sehingga ada kemungkinan mereka bisa menjalin persahabatan antar warga yang ada di wilayah tersebut.

Kebutuhan akan ruang publik di wilayah perkotaan sebenarnya, sudah banyak terpenuhi, mengingat keberadaan kota biasanya memiliki berbagai kebijakan dan regulasi terkait penataan wilayah, selain itu banyak pemerhati dan pengamat sosial yang peduli atau konsen terhadap pengembangan lingkungan khsusnya terkait ruang publik (Public Sphere), bahkan sebenarnya kebutuhan ruang publik bukan merupakan kebutuhan pokok atau primer, seperti: sandang, pangan dan papan. Hal tersebut bisa kita lihat dari berbagai ruang publik yang ada di kota kota besar, bagaimana masyarakat benar benar mendapatkan prioritas yang maksimal, agar wahana untuk menyalurkan ekspresi dan juga emosi dapat terwujud.

\section{Metodologi}

Penelitian ini berciri kualitatif dan menggunakan beberapa teknik pengumpulan data, seperti dokumentasi dengan menggunakan analisis kritis. Untuk mengetahui potensi ruang publik di daerah pedesaan.

Creswell (dalam Herdiansyah, 2010), menyebutkan: "Qualitative research is an inquiry process of understanding based on distinct methodological traditions of inquiry that explore a social or human problem. The researcher builds a complex, holistic picture, analizes words, report detailed views of information, and conducts the study in a natural setting". Penelitian kualitatif melibatkan penggunaan dan pengumpulan berbagai bahan empiris, seperti studi kasus, pengalaman pribadi, instropeksi, riwayat hidup, wawancara, pengamatan, teks sejarah, interaksional dan visual: yang benggambarkan momen rutin dan problematis, serta maknanya dalam kehidupan individual dan kolektif (Bungin, 2003).

\section{Hasil dan Pembahasan}

Ruang publik yang ada di daerah perkotaan, menjelma kedalam beberapa bentuk. Carr et al. (1992) menyusun tipologi ruang publik secara komprehensif berdasar seluruh penggunaan publik pada ruang-ruang kota sepanjang sejarah di Eropa dan Amerika Serikat. Pada tipologi yang dipaparkan oleh Carr, tidak terlihat penekanan dari segi bentuk geometrisnya. Klasifikasi Carr lebih menekankan kepada karakter kegiatan, lokasi dan proses 
pembentukannya. Carr membagi tipologi ruang publik menjadi 11 tipe:

1. Taman Publik

2. Square dan Plaza

3. Memorial

4. Pasar

5. Jalan

6. Taman Bermain

7. Ruang Terbuka untuk Komunitas

8. Jalur Hijau

9. Tempat Perbelanjaan

10. Ruang Spontan dalam Lingkungan Hunian

11. Tepi Air

Alhasil ruang publik didaerah perkotaan, bisa kita lihat seperti ilustrasi beberapa gambar yang telah kami susun, sebagai berikut:
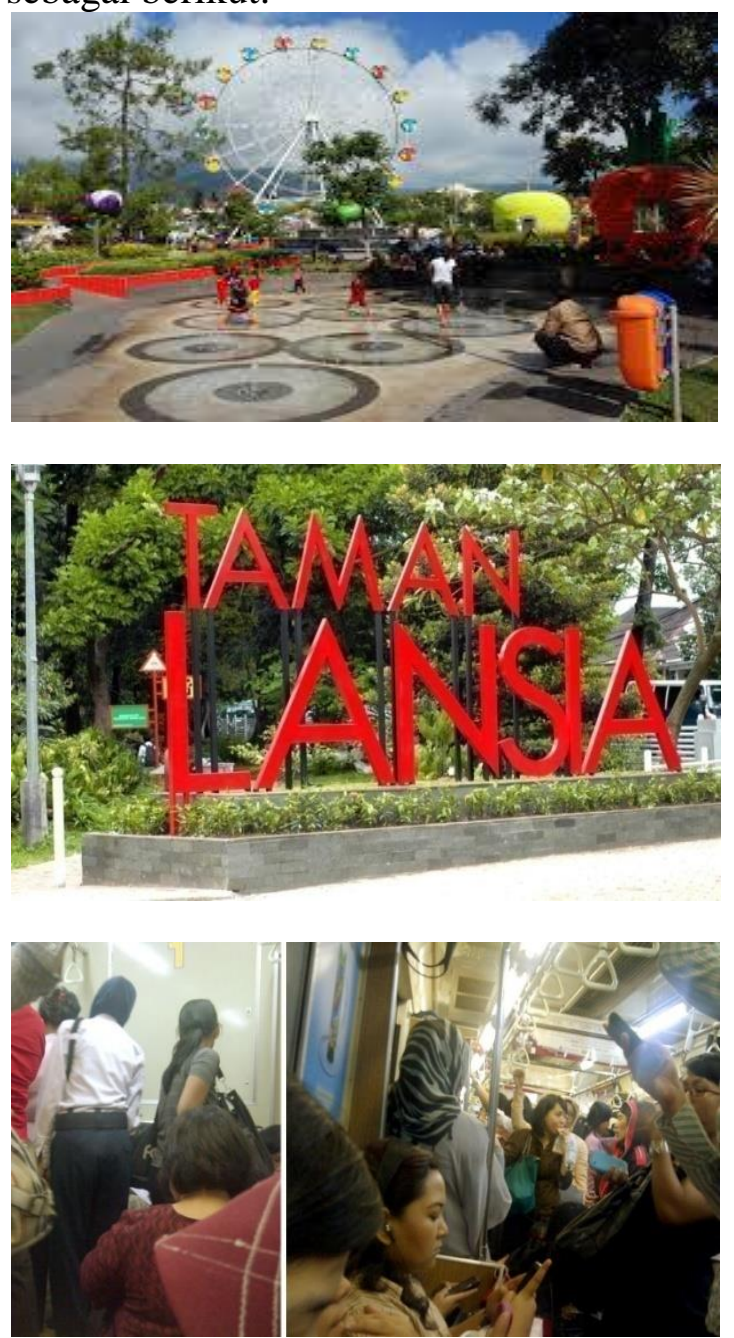

Gambar 1. Contoh Ruang Publik di wilayah Perkotaan

Walaupun sudah banyak terbentuk beberapa ruang publik, namun ada banyak kehawatiran, akan matinya ruang publik karena tidak membuat masyarakat di daerah perkotaan sadar pentingnya sinergitas dalam menjaga dan mengembangkan potensi tersebut. Pesimisme terhadap kemungkinan keberadaan dan keberlanjutan ruang publik, juga ditunjukkan Yasraf A. Piliang (dalam Wibowo, 2005: 21) melalui keraguannya: masih adakah masa depan bagi ruang publik dalam realitas kehidupan harian yang semakin dikendalikan oleh berbagai bentuk manipulasi, rekayasa dan simulasi realitas; berbagai pendangkalan, komodifikasi, dan banalitas; berbagai virtualisasi, manipulasi, dan simulasi; dan berbagai mitologisasi dan mistifikasi? Menurutnya, ini merupakan ancaman serius bagi keberadaan dan keberlanjutan ruang publik pada masa depan, disebabkan ia meminimalisir kualitas ruang publik itu sendiri sedemikian rupa sehingga pada suatu titik menghilangkan secara total elemen, struktur, sifat, dan karakteristiknya.

Belajar dari pengalaman yang ada, terkait penyelenggaraan dan pemanfaatan ruang publik yang dianggap berhasil oleh sebagian orang dan dianggap gagal oleh sebagain yang lain karena tidak bersifat partisipatif, maka ada satu pekerjaan rumah yang mungkin sangat tidak adil kalo kita abaikan, yaitu menggagas ruang publik yang ada di desa. Setelah kita mengupas tentang keberadaan ruang publik yang ada di wilayah perkotaan, tentu timbulah sebuah pertanyaan apakah di desa juga memerlukan keberadaan ruang publik, atau bahkan ada yang berpendapat bahwa desa tidak butuh hal tersebut dengan alasan, bahwa masyarakat desa lebih bahagia daripada masyarakat kota, menurut saya hal tersebut sangatlah tidak bijak, karena secara manusiawi pasti memiliki rasa bosan, jenuh dan juga perlu meluapkan ekspresi dalam satu kesempatan, mungkin juga perlu menyendiri untuk mencari inspirasi atau intropeksi terhadap kehiduapannya, oleh 
karena itu saya beasumsi jika desa juga perlu keberadaan sebuah ruang publik. Mengapa demikian, karena masyarakat desa juga memerlukan hiburan, dan komunitas masyarakat di pedesaan biasanya menghabiskan waktu liburan di ruang terbuka, misalnya masyarakat desa yang berada di wialayah pegunungan, mereka akan lebih tertarik untuk mengunjungi pantai laut ataupun daerah perkotaan yang selama ini jarang mereka jumpai di wilayah tersbeut, dan juga sebaliknya.

Kebutuhan akan ruang publik bagi masyarakat desa sebenarnya telah terpenuhi dan terlembaga, karena secara solidaritas masyarakat desa, memiliki beberapa wadah dalam berbagai bentuk dan model, sebagai sebuah sistem social yang terbentus atas dasar kekeluargaan dan gotong - royong, namun keberadaannya terkadang kurang dimaksimalkan, karena pola piker masyarakat desa saat ini juga mulai banyak berubah, karena tergerus oleh perkembangan zaman. Jika di kategorisasikan ada beberapa ruang publik yang potensial untuk dikembangkan, dan dimanfaatkan secara berkesinambungan sebagai bentuk pelembagaan dari berbagai praktik sistem sosial yang sudah ada, diantaranya: 1). Model ruang publik untuk pemenuhan fungsi aktualisasi kebudayaan. 2). Model ruang publik untuk pemenuhan kebutuhan organisasi. 3). Model ruang publik sebagai sarana pemenuhan kebutuhan keolahragaan. 3). Model pemenuhan ruang publik sebagai wahana spiritualitas, dan lain - lain. Model model tersebut memang terbentuk sebagai sebuah upaya komunitas masyarakat dalam memabangun solidaritas dan juga aktualisasi diri. Bentuk - bentuk pelembagaan tersebut bisa kita jumpai dalam kehidupan masyarakat, di daerah pedesaan, begitu juga yang ada di wilayah Kabupaten Ponorogo, sebagai salah satu model percontohanya, seperti ilustrasi dibawah ini:
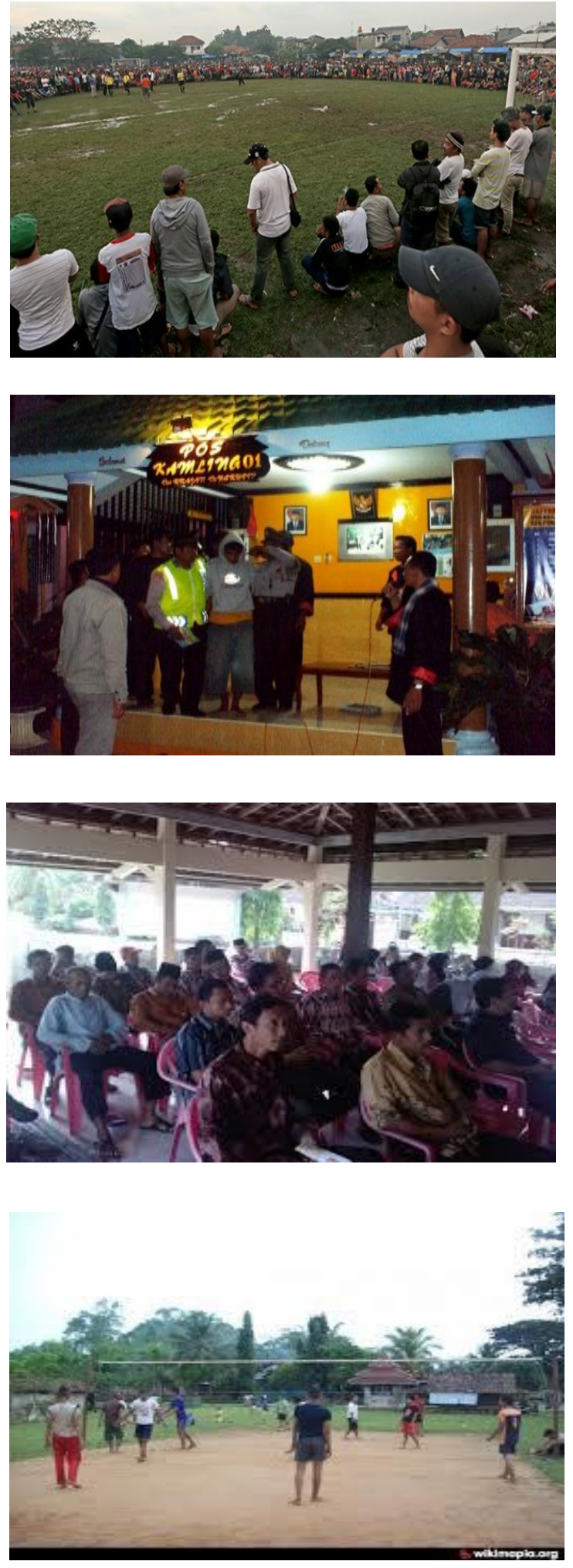

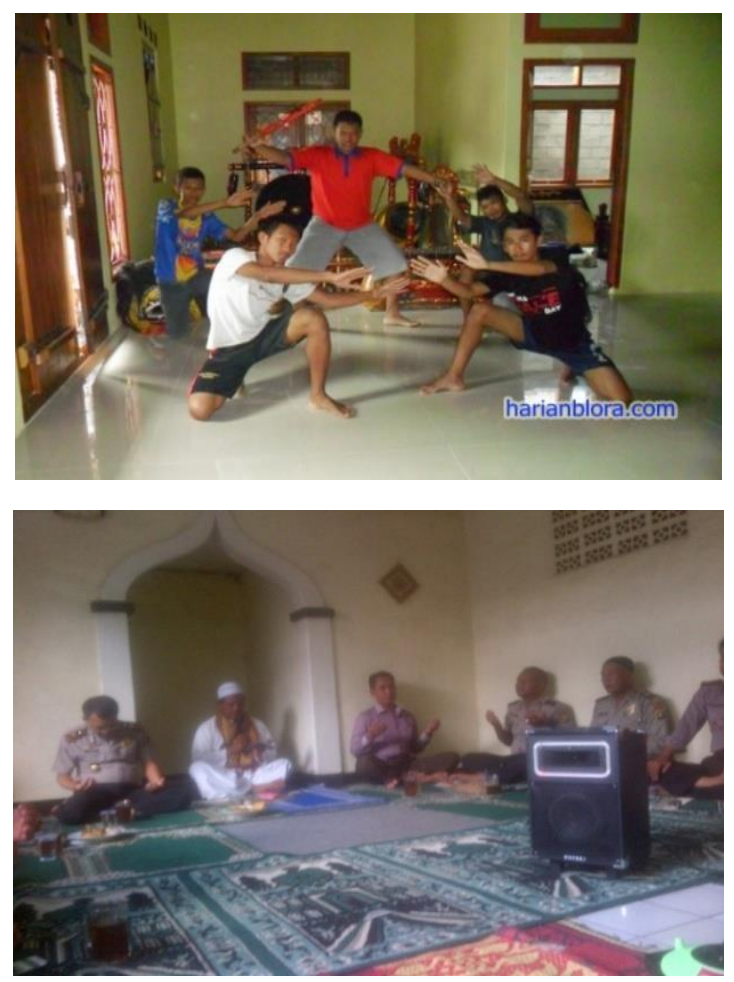

Gambar 2. Contoh Ruang Publik di wilayah Pedesaan

Konsep ruang publik di desa sebernarnya telah hadir dahulu, sebelum terbentuknya masyarakat modern, hal ini menandakan bahwa, potensi pengembangan dan pemanfaatannya, akan lebih baik dan maksimal dilakukan oleh masyarakat desa, karena seca kultur masyarakat desa, lebih toleran dengan solidaritas atau kesetiakawanaan yang tinggi dibandingkan masyarakat perkotaan yang cenderung lebih individualistis. Hal ini tentunya menjadi nilai lebih bagi masyarkaat desa untuk mengembangkan potensi tersebut.

Menurut Habermas dan Reimer orisinalitas ruang publik telah jauh-jauh hari ditemui bentuknya dalam tatanan masyarakat primitif prasejarah. Faktual, dalam rentang waktu senjang setelah periode-periode berburu dan meramu masyarakat primitif menggelar upacara adat sebagai simbol penghargaan pada dewa dan arwah leluhur yang telah memberkati perburuan. Pada satu sisi, upacara adat tersebut berfungsi pula sebagai sarana melepas lelah, kepenatan dan berbagai tekanan setelah masa berburu usai di mana setiap anggota masyarakat bebas mengambil dan menikmati daging atau makanan yang terkumpul (dalam John B. Thompson, 2006: 183)

\section{Penutup}

Fenomena tersebut menguatkan keyakinan kita, bahwa gagasan terkait ruang publik didaerah pedesaan, akan menemukan bentuk dan model baru, yang tidak kalah efektif dibandingkan konsep ruang publik yang ada di perkotaaan. Namun penekanan yang paling utama bagaimana ruang publik itu bisa dimanfaatkan dan dikelola oleh masyarakat secara mandiri dan berkesinambungan supaya dapat menjadi solusi terhadap pemenuhan kebutuhan masyarakat terhadap ruang publik. Menurut Juergen Habermas sebagai orang yang pertama kali memperkenalkan konsep ruang publik, menyebutkan bahwa syarat ruang publik adalah adanya komunikasi yang memungkinkan warganya membentuk wacana dan kehendak bersama secara bersama-sama

\section{Daftar Pustaka}

Bungin, Burhan. (2003). Analisis Data Penelitian Kualitatif. Jakarta: PT. Raja Grafindo Persada.

Carr, S., Francis, Mark., Rivlin, Leanne G. and Stone, Andrew M. (1992). Public Space. Cambridge: Cambridge University Press.

Herdiansyah, Haris. (2010). Metodologi Penelitian Kualitatif untuk Ilmu-Ilmu Sosial. Jakarta: Salemba Humanika.

John B. Thompson. (2006). Kritik Ideologi Global. Yogyakarta: IRCISOD.

Wibowo, Sunaryo Hadi (ed). (2005). Republik Tanpa Ruang Publik. Yogyakarta: Ire Press. 
